\title{
A RETROGRADE STUDY OF MYIASIS IN A TERTIARY CARE CENTRE
}

KEY WORDS: Myiasis,

Chrysomya, diptera, Maggots

\section{Dr. Ayesha Goel*}

\section{Dr. Ritu Nigam}

Resident, Department Of Otolaryngorhinology And Head And Neck Surgery, Gajra Raja Medical College, Gwalior *Corresponding Author

Associate Professor, Department Of Otolaryngorhinology And Head And Neck Surgery, Gajra Raja Medical College, Gwalior

Myiasis in head and neck region is a rare occurrence and is usually found in tropical countries like India. Poor hygiene, unsanitary living conditions, mental retardation, neglected wounds, diabetes mellitus and old age along with a warm and humid climate lay down a conducive environment for the larva of dipterous fly to infest humans. Maggots due to their tissue destructive properties can affect many regions in otolaryngorhinology like nasal cavity, ears, oral cavity, tracheostomy site ostoma, PNS, the skin and ulcerative lesions of head and neck. The burden of the disease lies in the fact that the complications range from minor tissue destruction, perforation of either the tympanic membrane, palate or septum, vertigo, angioedema to severe neurological manifestations, intracranial extension or rarely even death.

Objective: To assess the commonly affected age group and gender infested by myiasis, it's seasonal trend, socioeconomic status of the affected patients and the relationship of myiasis infestation with various predisposing factors.

Methodology: Retrograde study was conducted on 95 patients of department of otorhinolaryngology. The study was done from January 2015 to October 2018 by collecting data of 3 years 10 months time interval and results tabulated. Ethical clearance was sort and patients consent obtained.

Result: The most commonly affected age group was found to be elderly, in the 7 th decade of life (56.84\%). Females were more commonly affected than males consisting of 55 out of 95 cases (57.89\%), with a male female ratio of 1:1.4. Majority of cases presented in the months of October-January, with a peak in November (32/95). Nasal myiasis was found to be more common (69 cases) in comparison to aural and oral cavity myiasis. The most common predisposing factor was found to be Atrophic Rhinitis in $66.7 \%$ cases.

Conclusion : With awareness and improved personal hygiene a devastating disease like myiasis is easily preventable and curable.

\section{INTRODUCTION :}

Maggots due to their tissue destructive properties can affect many regions in otolaryngorhinology like nasal cavity, ears, oral cavity, tracheostomy site ostoma, pns, the skin and ulcerative lesions of head and neck.The eggs hatch in between 8 hours to 3 days depending on the climate, into milky white colored larvae. Around 86 different species of flies have been shown to cause myiasis in human beings. The fly may lay eggs or larvae onto foodstuffs causing chance infection following ingestion (known as accidental myiasis), or eggs or larvae may be laid directly on to necrotic tissue in wounds (semi-specific myiasis) or some species of flies may require living tissue and lay eggs directly onto undamaged skin (obligatory myiasis) ${ }^{(1)}$. Myiasis in maxillofacial region is more commonly associated with predisposing anatomical, physical and medical conditions which include mouth breathing habit, incompetence of lips, cerebral palsy, parkinsonism, epilepsy, extraction socket, neglected maxillofacial and mandibular trauma, patients undergoing mechanical ventilation, alcoholism and senility and certain local pathological conditions such as cancrum oris and oral malignancies $^{(2)}$. Myiasis can be classified as either obligatory or facultative infestation. It is usually diagnosed by history and clinical examination. The symptoms begin after deposited larvae begin to feed on surrounding tissue.the adult female flies gets attracted to the odoriferous or pus filled lesions, open wounds, necrotic material or soft skin or mucosa of any part that are contaminated by blood or mucous discharge. The maggots on hatching penetrate deeper into the tissue aided by their sharp mouth hooks and anchoring inter segmental spines. This leads to progressive necrosis of the tissue associated with larval growth and invasion which in turn leads to tense and oedematous surrounding tissue emitting a characteristic odour. Pathogenecity results from inflammation and toxin secreted by the larvae which prevents healing. Myiasis is further classified as either primary myiasis, when larvae feed on living tissue or secondary myiasis, when larvae feed on dead tissue. Depending on the mode of infestation it is of three types ;

1. Accidental myiasis, when larvae gets ingested along with food

2. Semi-specific myiasis, when larvae are laid on necrotic tissue of the wound

3. Obligatory myiasis, when fly larvae are completely parasitic and depend upon the host for completion of their life cycle.

Simple technique of forceps removal of larvae on instillation of turpentine oil followed by irrigation of the cavity with either chloroform, normal saline, ivermectin or iodine to extrude remnants is a safe and effective way of treatment of myiasis. This is combined with prophylactic systematic broad spectrum antibiotics to prevent secondary infection. Sometimes surgical exploration is needed when there is suspicion of about extent of disease or residual disease.

AIM : To assess the commonly affected age group and gender infested by myiasis, it's seasonal trend, socioeconomic status of the affected patients and the relationship of myiasis infestation with various predisposing factors.

\section{MATERIAL AND METHODS :}

A retrograde study was conducted on a total of 95 ward and OPD patients of department of Otorhinolaryngology and head and neck surgery. The study was done from January 2015 to October 2018 by collecting data of 3 years 10 months time interval and result tabulated. Detailed patient history was sought and followed by local and systemic examination. All the patients belonged to lower socio economic strata. The nasal cavity was examined for chronic granulomatous diseases, tumors and infections. X-ray Paranasal sinus was done to look for sinusitis as a predisposing factor. The Ear was examined for signs of acute or chronic otitis media, wounds and masses. Oral cavity was examined for oral hygiene, halitosis, growth/ lesions, and site of tooth extraction if any. 
Ethical clearance was sort and patients consent obtained.

RESULT: In the present study of 95 patients it was found that the most commonly affected age group was elderly, in the $7^{\text {th }}$ decade of life (56.84\%)

Females were found to be more commonly affected than males consisting of 55 out of 95 cases (57.89\%), with a male female ratio of 1:1.4. Majority of cases presented in the months of october-january, with a peak in November (32/95). Nasal myiasis was found to be more common (69 cases) in comparison to aural(18 cases out of 95) and oral cavity myiasis(5/95). 2 cases of trachesotomy ostoma myiasis and 1 case of oral cancer site myiasis were also included in the study.

Out of 95 cases 38 belonged to lower socioeconomic class (SEC) with score below 5, 53 cases belonged to upper lower SEC with scores between 5-10, and 4 cases belonged to lower middle SEC with scores between 11-15( Modified kuppuswamy scale).

The most common overall predisposing factor was poor hygiene and low socio economic status. Atrophic rhinitis was found to be the most common in $66.7 \%$ cases of nasal myiasis , followed by sinusitis in 46 out of 69 cases of nasal myiasis. Socioeconomic Status Of Patients With Myiasis

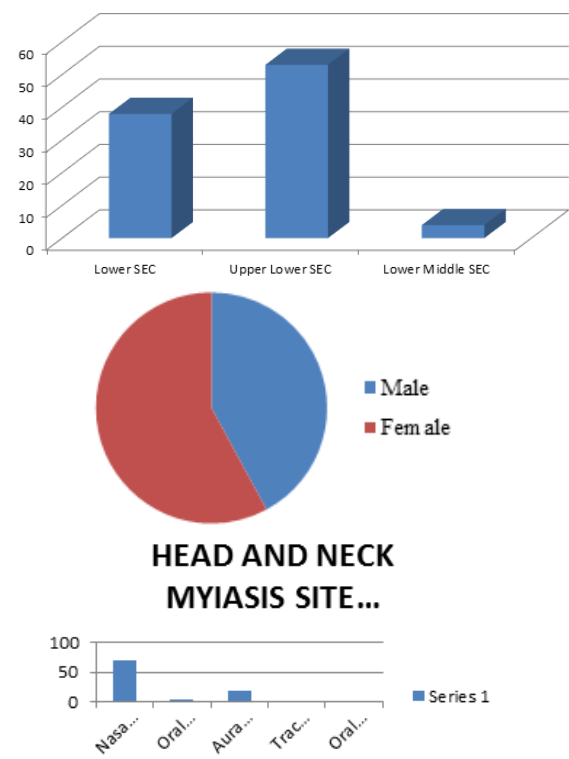

\section{DISCUSSION :}

Flies causing myiasis belong to the order diptera. Chrysomya bezziana, a blue green colored fly also known as "old world screwworm" is the cause of majority cases of myiasis reported in india. Its life cycle from egg to adult takes 18days to complete with the adult female laying over 150-200 eggs every 2 days at the site of wound. Egg hatches after 12-18 hrs and the $1^{\text {st }}$ stage i.e larva, whitish in color emerges and burrows into the tissue. After 5-7 days the larva pupates and falls to the ground to pupate and transform into adult flies. C. Bezianna differs from other maggots by its ability to cause tissue invasion even without pre existing necrosis ${ }^{(3)}$.

In the present study female were seen to be affected more by myiasis compared to males (55 out of 95 cases) which Is consistent with A study conducted by Singh et al. in 1993 on myiasis found that $57.8 \%$ cases were females and $41.8 \%$ cases were males ${ }^{(4)}$

The social data of all patients was collected and analysed. Out of 95 cases 38 belonged to lower socioeconomic class (SEC) with score below 5, 53 cases belonged to upper lower SES with scores between 5-10, and 4 cases belonged to lower middle SEC with scores between 11-15.A study by Gabriel et al. in 2008 on oral myiasis and a case report by Al Jabr in 2015 on aural myiasis also support that poor SEC, illiteracy, and poor hygiene were significant predisposing factors for myiasis. ${ }^{(5)}$

Nasal myiasis was found to be more common (69 cases) in comparison to aural(18 cases out of 95) and oral cavity myiasis(5/95) this is in consistence with a study by Arora et where nasal myiasis represented $70 \%$ to $75 \%$ of ENT myiasis cases. $^{(7)}$

In our study, Atrophic rhinitis was found to be the most common in $66.7 \%$ cases of nasal myiasis which is in accordance to a study by Arora S. et al wherein Atrophic turbinates was the commonest pathological finding in nose in $30 \%$ of cases. . $^{(8)}$

Majority of cases presented in the months of October-January, with a peak in November (32/95) in our study. Various studies (Bhatia et al. and Sood VP et al P) ${ }^{(9),(10)}$ had slight variations in peak months, however, majority concluded majority cases in winters followed by rainy season.
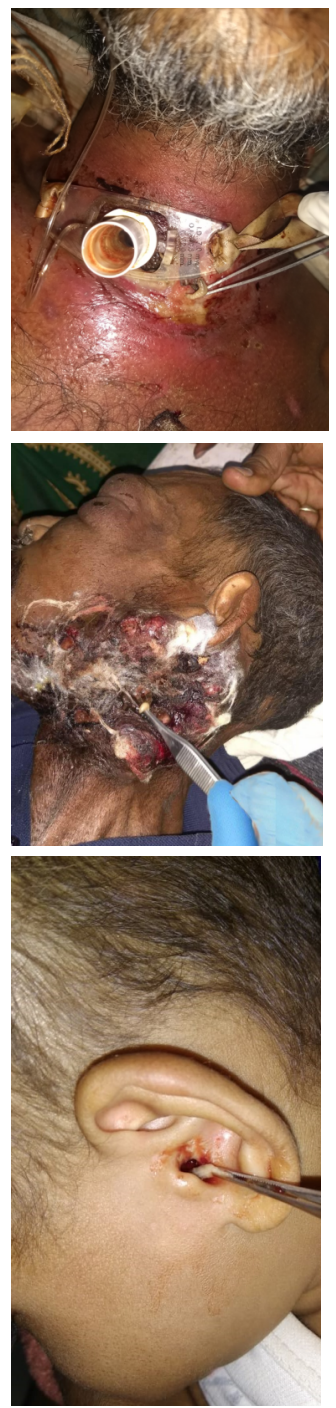

\section{CONCLUSION :}

In conclusion, the present study shows that with proper basic hygiene measures and improved socio economic status, Myiasis is a preventable disease which can be efficiently 
controlled conservatively so as to reduce its burden on the healthcare system and minimalise patient discomfort.

\section{REFERENCES :}

(1) Krajewski A. Allen B. Hoss D. Patel C. Chandawarkar RY. Cutaneous myiasis. Journal of Plastic, Reconstructive \& Aesthetic Surgery: JPRAS. 62(10):e383-6, 2009 Oct. [Case Reports. Journal Article. Review]

(2) Krajewski A. Allen B. Hoss D. Patel C. Chandawarkar RY. Cutaneous myiasis. 2009 Oct. [Case Reports. Journal Article. Review]

(3) Nene AS, Mishra A, Dhand P. Ocular myiasis caused by Chrysomya bezziana a case report. Clin Ophthalmol. 2015;9:423-427. Published 2015 Mar 3. doi:10.2147/OPTH.S79754

(4) Singh I, Gathwala G,Yadav SP,Wig U,Jakhar KK. Myiasis in children:The Indian perspective. Int J Pediatr Otorhinolaryngol 1993;25:127-31.

(5) Al Jabr I. Aural myiasis, a rare cause of earache. Case Rep Otolaryngol 2015;2015:219529.

(6) Francesconi F, Lupi O. Myiasis. Clin Microbiol Rev. 2012;25(1):79-105. doi:10.1128/CMR.00010-11

(7) clinical etiology of myiasis in ENT: a reterograde period--interval study Arora S, Sharma JK, Pippal SK, Sethi Y, Yadav A Braz J Otorhinolaryngol. 2009 May-Jun; 75(3):356-61.

(8) Arora S, Sharma JK, Pippal SK, Sethi Y,Yadav A. Clinical etiology of myiasis in ENT: a reterograde period--interval study. Braz J Otorhinolaryngol. 2009;75(3):356-361.doi:10.1016/s1808-8694(15)30651-0

(9) ML Bhatia, KDuttaMyiasis of the tracheostomy wound JLO (79) (1965), p.907

(10) VP Sood, PK Kakkar,VLVattal J.L.O, 393 (1975), p. 1976 